\title{
Hemşirelerin Meme Kanseri, Kendi Kendine Meme Muayenesi ve Mamografiye İlişkin İnançlarının Belirlenmesi
}

\section{Determination of the Beliefs of Nurses Regarding Breast Cancer, Self Breast Examination and Mammography}

\author{
Nazife Bakır ${ }^{1 *}$, Cuma Demir ${ }^{1}$ \\ ${ }^{1}$ Burdur Mehmet Akif Ersoy Üniversitesi Bucak Sağlık Yüksekokulu \\ e-mail: nazbakir@hotmail.com, saidcumademir0207@gmail.com \\ Orcid: 0000-0003-1324-0647 \\ Orcid: 0000-0003-3361-8547 \\ *Sorumlu Yazar / Corresponding Author: Sorumlu Yazar: Nazife Bakır ${ }^{1}$ \\ Gönderim Tarihi / Received: 09.12.2019 \\ Kabul Tarihi / Accepted: 07.04.2020 \\ DOI: $10.34087 /$ cbusbed.657109
}

Giriş: Araştırma hemşirelerin meme kanseri, kendi kendine meme muayenesi ve mamografiye ilişkin inançlarının belirlenmesi amacıyla yapılmıştır.

Gereç ve Yöntemler: Araştırmanın evreni Burdur Devlet Hastanesi ve Bucak Devlet Hastanesi'nde çalışan 450 hemşire oluşturmaktadır. Örneklemi ise araştırmaya katılmayı kabul eden 358 hemşire oluşturmuştur. Veri toplama formu olarak; tanımlayıcı form ve Sağlık İnanç Modeli Ölçeği kullanılmıştır

Bulgular: Araştırma kapsamında hemşirelerin \%7,2'sinin ailesinde meme kanseri öyküsü olduğu belirlenmiştir. Sigara kullanmayanların sağlık motivasyonu ve kendi kendine meme muayenesi öz etkililiği anlamlı düzeyde yüksek olduğu saptanmıştır. Ailesinde meme kanseri olan hemşirelerin duyarlılık ve sağlık motivasyonu algıları istatistiksel olarak anlamlı düzeyde yüksek bulunmuştur.

Sonuç: Hemşirelerin eğitim düzeyi, yaşı, cinsiyeti, sigara kullanması ve ailesinde meme kanseri olma; Champion'un Sağlık İnanç Modeli Ölçeği alt boyutlarının puan ortalamalarını etkilediği saptanmıştır.

Anahtar Kelimeler: Hemşire, meme, kanser

\footnotetext{
Abstract

Objective: The research was conducted to determine the nurses' beliefs about breast cancer, breast self-examination and mammography.

Materials and Method: The population of the study consists of 450 nurses working in Burdur State Hospital and Bucak State Hospital. The sample consisted of 358 nurses who accepted to participate in the study. Data were collected by introductory information form and health belief model scales.

Results: Within the scope of the research, it was determined that 7,2\% of the nurses had a family history of breast cancer. Health motivation and breast self-examination self-efficacy of non-smokers were significantly higher.

Sensitivity and health motivation perceptions of the nurses who had breast cancer in their family were found to be significantly higher.

Conclusion: Nurses' education level, age, gender, smoking and family breast cancer; Champion's Health Belief Model Scale subscales were found to affect the mean scores.

Key words: Nurse, breast, cancer

1. Giriş

Kanser, ölüm sebebi olması nedeniyle tüm dünyada olduğu gibi Türkiye'de de en önemli sağlık problemi olarak karşımıza çıkmaktadır [1]. Kadınlar arasında en yaygın olarak görülen kanser türü meme kanseridir [2,3]. Meme kanseri kadınlarda kansere bağlı olan ölümlerin $\% 18$ 'ini oluşturmaktadır [3]. Meme kanserinin ortaya çıkmasına neden olan bazı risk faktörleri

arasında; ileri yaş, cinsiyet (kadın olmak), aile öyküsü, infertilite, erken menarş, geç menapoz, 1rk, laktasyon, doğum sayısı, gebelik yaşı, östrojen replasmanı tedavisi, alkol kullanımı, radyasyona maruz kalma, genetik yatkınlık, obezite, sedanter yaşam tarzı, sigara kullanımı, emzirmeme, kimyasal maddeler ve ilaçlar, meme kanseri riskiyle alakalı gen mutasyonları veya
} 
BRCA1/2, p53, PTEN varlı̆̆ının olması sayılabilir [4-6]. Meme kanserinin erken tanısı ve tedaviyle kontrol altına alınması; morbidite ve mortalitenin azalmasını, yaşam kalitesinin yükseltilmesini, yaşam süresinin uzamasını, erken evrede tanı ile meme koruyucu tedavi seçeneklerinin sağlanmasını ve oluşabilecek psikososyal sorunların gidermesini sağlamaktadır [7]. Son zamanlarda yaygın olarak kullanılan kendi kendine meme muayenesi (KKMM), klinik meme muayenesi ve mamografi yöntemi meme kanserinin erken tanı ve teşhisinde etkin olarak kullanılmakta ve sağ kalım şansını arttırmaktadır [8-10]. KKMM, kadınların meme dokusundaki şekil değişikliklerini erken dönemde belirleyebilmek ve erken evre meme kanserini yakalayabilmeleri için kendi kendilerine yaptıkları bir muayene şeklidir. KKMM, kadınların 20 yaşından itibaren, yaşamları süresince adet döneminin 5-7. günlerinde düzenli olarak her ay kendi memelerini kontrol etmeleridir. Menopoz sonrasi ve menstrual siklusları düzenli olmayan kadınlarda ise her ay kendileri tarafından belirledikleri bir günde düzenli olarak meme muayenesi yapmalarıdır [11]. Meme muayenesi, her kadının evinde tek başına ayakta dururken veya banyoda yıkanırken kolaylıkla uygulayabileceği ekonomik, güvenilir, tehlikesi olmayan herhangi bir alet gerektirmeyen, invaziv olmayan rahat bir yöntemdir $[9,11]$.

Mamografi, fizik muayenede ortaya çıkamayacak derecede küçük anomalileri belirlemek amacıyla çekilen meme dokusunun röntgen filmidir. Bir tarama aracı olan mamografi, aynı zamanda memede gelişen sertlik, şekil değişikliği, hassasiyet ve memede akıntı gibi anormal durumlara tanı koymak için de kullanılır [10]. Mamografi ile meme kanseri taramasının yapılması, meme kanserinin erken, tedavi edilebilir bir aşamada tespit edilmesini sağlamaktadır $[12,13]$. Dünya Sağlik Örgütü'ne göre 50-69 yaş arası kadınlarda mamografiyle tarama yapılması $\% 40$ civarında mortalitede bir azalma olduğunu bildirmiştir. Amerikan Kanser Derneği tarafindan 40-49 yaşlarındaki kadınların 1-2 yılda tek sefer, 50 yaş ve üzeri olan kadınlar için ise her yıl mamografi çektirilmesi gerektiğini önerilmektedir [10]. $\mathrm{Bu}$ araştırmanın amacı Burdur ilinde iki devlet hastanesinde çalışan hemşirelerin meme kanseri, KKMM ve mamografiye ilişkin inançlarını belirlemektir.

\section{Materyal ve Metot}

\subsection{Araştırmanın yapıldığı yer ve zaman}

Nicel ve tanımlayıcı tipteki bu araştırma 15 Temmuz -15 Ağustos 2019 tarihleri arasında Burdur Devlet Hastanesi ve Bucak Devlet Hastanesi'nde görev yapan hemşirelerle yürütülmüştür.

\subsection{Evren ve örneklem}

Araştırmanın evreni Burdur Devlet Hastanesi ve Bucak Devlet Hastanesi'nde çalışan 450 hemşire oluşturmaktadır. Araştırmada evrenin tamamına ulaşılması hedeflenmiş olup araştırmanın yapıldığı tarihlerde izinli olmayan ve araştırmaya katılmayı kabul eden 358 hemşire örneklemi oluşturmuştur.

\subsection{Veri toplama araçları}

Hemşirelere "Tanımlayıcı özellikler formu" ve "Meme Kanseri Taramalarında Champion'un Sağlık İnanç Modeli Ölçeği” uygulanmıştır.

\subsubsection{Tanımlayıcı özellikler formu}

Hemşirelerin sosyo-demografik özelliklerini incelemeyi sağlayan; yaş, cinsiyet, eğitim düzeyi, medeni durum, çocuk sayısı, aile gelir durumu, hangi klinikte çalıștı̆ı̆, ailesinde meme kanseri bulunma, sigara ve alkol kullanma durumunu sorgulayan 10 sorudan oluşmaktadır.

2.3.2 Meme Kanseri Taramalarinda Champion'un Sağllk İnanç Modeli Ölçeği (CSIMMÖ)

Victoria Champion tarafindan 1984 yılında meme kanseri ve KKMM'ye ilişkin inançları ölçmek için geliștirilen ilk formu, 1997 de ölçeğin KKMM'ye ilişkin boyutlarını tekrar revize edilmiş ve mamografiye ilişkin iki yeni alt boyut (mammografi engelleri ve mammografi yararları) eklenmiştir. Bu düzenlemede Cronbach alpha güvenirlik kat sayıları .65 ile .90 , test- tekrar test korelasyonları ise .40 ile .68 arasında saptanmıştır. Türkçeye uyarlanması Gözüm ve ark. [14] tarafindan yapılan ölçeğin, bireyin meme kanseri ve genel sağlığı ile ilgili yargısını değerlendiren "duyarlılık", "Önemseme/ciddiyet" ve "sağlık motivasyonu", KKMM ile ilgili "engelleri”, "yararları" "öz etkililiği/güven”, mamografi ile ilgili "yararları" ve “engelleri” boyutları vardır. Ölçeğin hangi boyutlarının kullanılacağı çalışmanın amacı ve çalışma grubunun özelliklerine göre değişir. Ölçek 5'li likert tipindedir. $\mathrm{Bu}$ araştırmanın Cronbach alpha değeri Tablo 2 de verilmiştir.

\subsection{Verilerin toplanmast}

Veriler araştırmacılar tarafindan Burdur Devlet Hastanesi ve Bucak Devlet Hastanesi'nde çalışan Hemşirelere normal tedavi ve bakım işleyişini bozmadan uygun vakitlerde araştırmacılar tarafindan yüz yüze görüşme yöntemi ile toplanmıştır.

\section{5 İstatistiksel analiz}

Araştırmada elde edilen verilerin değerlendirilmesinde SPSS 20.0 paket programı kullanılmış olup, yüzde, frekans, One-Way ANOVA, Indenpendent Samples ttest kullanılmıştır. Anlamlılık düzeyi $\mathrm{p}<0,05$ olarak kabul edilmiştir

\subsection{Etik}

Araştırmaya başlamadan önce Mehmet Akif Ersoy Üniversitesi Girişimsel Olmayan Klinik Araştırmalar Etik Kurulu onayı (Tarih: 03.04.2019 Karar No: GO 2019/60) alınmıştır. Araştırmaya katılan hemşirelere araştırmanın amacı ile ilgili bilgi verilip elde edilen bilgilerin sadece bu araştırma için kullanılacağı açıklandıktan sonra, sözlü ve yazılı onamları da alınmıştır.

\section{Bulgular}

Araştırmaya katılan hemşirelerin \%44,1'i 32-38 yaş arasında olduğu, \%84,4' ünün kadın hemşire olduğu, $\% 43,2$ 'sinin eğitim düzeyi ön lisans olduğu ve $\% 87,7$ 'sinin medeni durumunun evli olduğu saptanmıştır. 
Tablo 1. Hemşirelerin tanıtıcı özelliklere göre dağılımı

\begin{tabular}{|c|c|c|}
\hline Tanıtıcı özellikler $(n=359)$ & $\mathbf{N}$ & $\%$ \\
\hline \multicolumn{3}{|l|}{ Yaş } \\
\hline $18-24$ & 12 & 3.3 \\
\hline $25-31$ & 68 & 18.9 \\
\hline $32-38$ & 158 & 44.1 \\
\hline 39 ve üzeri & 121 & 33.7 \\
\hline \multicolumn{3}{|l|}{ Cinsiyet } \\
\hline Kadın & 303 & 84.4 \\
\hline Erkek & 56 & 15.6 \\
\hline \multicolumn{3}{|l|}{ Eğitim düzeyi } \\
\hline Lise & 27 & 7.5 \\
\hline Ön lisans & 155 & 43.2 \\
\hline Lisans & 142 & 39.6 \\
\hline Lisansüstü & 35 & 9.7 \\
\hline \multicolumn{3}{|l|}{ Medeni durumu } \\
\hline Evli & 315 & 87.7 \\
\hline Bekar & 44 & 12.3 \\
\hline \multicolumn{3}{|l|}{ Kaç çocuk var } \\
\hline Çocuk yok & 58 & 16.2 \\
\hline $1-2$ çocuk & 191 & 53.2 \\
\hline 3-4 çocuk & 92 & 25.6 \\
\hline 5 ve üzeri & 18 & 5.0 \\
\hline \multicolumn{3}{|l|}{ Aile gelir durumu } \\
\hline Gelir giderden az & 92 & 25.6 \\
\hline Gelir gidere eşit & 158 & 44.0 \\
\hline Gelir giderden fazla & 109 & 30.4 \\
\hline \multicolumn{3}{|l|}{ Hangi klinikte çalışıyor } \\
\hline Cerrahi klinikler & 200 & 55.7 \\
\hline Dahiliye klinikler & 159 & 44.3 \\
\hline \multicolumn{3}{|l|}{ Sigara kullanma durumu } \\
\hline Evet & 87 & 24.2 \\
\hline Hayır & 272 & 75.8 \\
\hline \multicolumn{3}{|l|}{ Alkol kullanma durumu } \\
\hline Evet & 20 & 5.6 \\
\hline Hayır & 339 & 94.4 \\
\hline \multicolumn{3}{|c|}{$\begin{array}{l}\text { Ailede meme kanseri olan var } \\
\text { mı? }\end{array}$} \\
\hline Evet & 26 & 7.2 \\
\hline Hayır & 333 & 92.8 \\
\hline Toplam & 359 & 100 \\
\hline
\end{tabular}

Katılımcıların \%53,2'sinin 1-2 çocuğa sahip olduğu, $\% 44,0$ 'ının gelirinin gidere eşit olduğu, \%38,2'si 11-16 yıldır çalıştığı ve \%55,7'si ise cerrahi kliniklerinde çalıştığ 1 belirlenmiştir. Yine \%24,2'sinin sigara kullandığ $1, \% 5,6$ 'sının alkol kullandığı ve 7,2'sinin ise ailesinde meme kanseri öyküsü olduğu saptanmıştır (Tablo 1).
Tablo 2'de hemşirelerin meme kanseri taramalarında CSIMÖ alt boyutlarından aldıkları puanlar incelendiğinde; hemşirelerin duyarlılık alt boyut puan ortalaması $8,41 \pm 2,09$, önemseme/ciddiyet alt boyut puan ortalaması $26,81 \pm 5,75$, sağlı motivasyonu alt boyut puan ortalaması $20,59 \pm 2,57$, KKMM yararları alt boyut puan ortalamasi $15,39 \pm 2,66, \mathrm{KKMM}$ engelleri alt boyut puan ortalamasi 20,76 $\pm 4,38$, KKMM özetkililiği alt boyut puan ortalaması 34,66 $\pm 5,99$, mamografi yararları alt boyut puan ortalaması $18,79 \pm 3,23$ ve mamografi engelleri alt boyut puan ortalaması 26,81 $\pm 5,75$ olarak bulunmuştur.

Tablo 2. Meme kanseri taramalarında Champion'un Sağlık İnanç Modeli Ölçeği puan ortalamalarının dağılımı

\begin{tabular}{|l|l|l|l|}
\hline $\begin{array}{l}\text { CSIMÖ Alt } \\
\text { boyutları }\end{array}$ & $\begin{array}{l}\text { Ortalam } \\
\text { a }\end{array}$ & SS & $\begin{array}{l}\text { Cronbac } \\
\text { halpha }\end{array}$ \\
\hline Duyarlılık & 8,41 & 2,53 & 0,61 \\
\hline $\begin{array}{l}\text { Önemseme } \\
\text { Ciddiyet }\end{array}$ & 26,81 & 5,75 & 0,54 \\
\hline Sağlık Motivasyonu & 20,59 & 2,57 & 0,65 \\
\hline $\begin{array}{l}\text { KKMM yararları } \\
\text { KKMM engelleri }\end{array}$ & 20,76 & 4,38 & 0,67 \\
\hline $\begin{array}{l}\text { KKMM } \\
\text { öz etkililiği }\end{array}$ & 34,66 & 5,99 & 0,68 \\
\hline $\begin{array}{l}\text { Mamografi } \\
\text { Yararları }\end{array}$ & 18,79 & 3,23 & 0,71 \\
\hline $\begin{array}{l}\text { Mamografi } \\
\text { Engelleri }\end{array}$ & 26,81 & 5,75 & 0,78 \\
\hline Ort: Ortalama, ss: Stand & & 0,60 \\
\hline
\end{tabular}

Ort.: Ortalama, ss: Standart sapma

Tablo 3'de meme kanseri taramalarında CSIMÖ'nün tanıtıcı özelliklere göre dağılımı verilmiştir. 18-24 yaş grubundaki hemşirelerin meme kanseri taramalarında CSIMÖ sağlıkmotivasyonu alt boyutu puan ortalaması 25-31 yaş grubu hemşirelerin puan ortalamasından istatistiksel olarak anlamlı düzeyde yüksek olduğu saptanmıştır.

Erkek hemşirelerin KKMM engelleri ve mamografi yararları alt boyutu puan alt puan ortalaması kadın hemşirelerin puan ortalamalarından istatistiksel olarak anlamlı düzeyde yüksek olduğu saptanmıştır. Kadın hemşirelerin KKMM öz etkililiği alt puan ortalaması erkek hemşirelerin puan ortalamalarından istatistiksel olarak anlamlı düzeyde yüksek olduğu belirlenmiştir. Eğitim düzeyi lise olan hemşirelerin KKMM öz etkililiği alt boyutu puan ortalaması eğitim düzeyi ön 
lisans, lisans ve lisansüstü olan hemşirelerin puan ortalamalarında istatistiksel olarak anlamlı düzeyde düşük olduğu saptanmıştır. Eğitim düzeyi ön lisans olanların meme kanseri taramalarında CSIMÖ mamografi engelleri alt boyutu puan ortalaması lisans mezunu hemşirelerin puan ortalamasından istatistiksel olarak anlamlı düzeyde yüksek olduğu saptanmıștır.

Sigara kullanmayanların sağlık motivasyonu ve KKMM öz etkililiği alt boyutu puan ortalaması sigara kullananların puan ortalamasından istatistiksel olarak anlamlı düzeyde yüksek olduğu belirlenmiştir.

Ailesinde meme kanseri öyküsü olanların duyarlılık ve sağlık motivasyonu alt boyutları puan ortalaması ailesinde meme kanseri olmayanların puan ortalamasından istatistiksel olarak anlamlı düzeyde yüksek olduğu saptanmıştır. Ailesinde meme kanseri öyküsü olmayanların meme kanseri taramalarında CSIMÖ mamografi engelleri alt boyutu puan ortalaması ailesinde meme kanseri olanların puan ortalamasından istatistiksel olarak anlamlı düzeyde yüksek olduğu saptanmıştır.

\section{Tartışma}

Sağlık inanç modelinde kişinin engel algısının düşük olması, yarar ve öz etkililik algısının yüksek olması, sağlık davranışına başlama olasılığının yüksek olacağını gösterir [15]. Bu çalışmada hemşirelerin meme kanseri taramalarında CSIMÖ alt boyutlarından aldıkları puanlar duyarlılık $8.41 \pm 2.09$, önemseme/ ciddiyet $26,81 \pm 5,75$, sağlık motivasyonu $20,59 \pm 2.57$, KKMM yararları 15,39 $\pm 2,66$, KKMM engelleri 20,76 $\pm 4,38$, KKMM öz-etkililiği 34,66 $\pm 5,99$, mamografi yararları $18,79 \pm 3,23$ ve mamografi engelleri 26,81 $\pm 5,75$ olarak bulunmuştur. Buna göre KKMM öz-etkililiği 34,66 $\pm 5,99$ puanı yüksek olmakla birlikte; KKMM yararları ve mamografi yararları puanlarının, KKMM engelleri ile Mamografi engellerinden daha düşük olduğu saptanmıştır. Arevian ve ark. [16] Lübnan'da Ermeni kadınlar ile yaptığı çalışmada CSİMÖ alt boyutlarından aldıkları puan ortalamaları, duyarlılık 14,32, KKMM engelleri 15,24, mamografi engelleri 14,85, önemseme/ciddiyet 23,42, KKMM yararları 22,70, güven 36.45 , sağlık motivasyonu 27,20 ve mamografi yararları 24,28 olarak belirlenmiştir. Pirzadeh'in [17] çalışmasında ise sağlık inanç modeli yapılarının ortalama puanları, algilanan duyarlilık 8.77 \pm 4.16 , algilanan ciddiyet $24,63 \pm 5,80$, algilanan faydalar $22.96 \pm 12.86$ ve algilanan engeller $27,21 \pm 17,18$ olarak hesaplanmıştır. Birinci basamak sağlık kurumlarındaki hemşireler arasında meme kanseri riskinin ve meme kanseri taramasına inanmanın değerlendirilmesine yönelik yapılan bir çalışmada da puan ortalamaları, duyarlılık $7,3 \pm 1,8, \quad$ ciddiyet/önemseme $\quad 19,5 \pm 4,1, \quad$ KKMM yararları 15,5 $\pm 2,6$, KKMM engelleri $15,1 \pm 2,8$, öz yeterlilik $40,3 \pm 7,0$ ve motivasyon $19,5 \pm 4,1$ olarak saptanmıştır [18]. Literatür incelendiğinde farklı çalışmalarda alt boyut ortalamalarının farklılık gösterdiği görülmektedir [15,19,20].
Bu çalışmada 18-24 yaş grubundaki hemşirelerin meme kanseri taramalarında CSIMÖ sağlık motivasyonu alt boyutu puan ortalaması 25-31 yaş grubu hemşirelerin puan ortalamasindan istatistiksel olarak anlamlı düzeyde yüksek olduğu saptanmıştır. Alvur ve ark. [21] çalışmasında ise yaşı büyük olan kadınların KKMM öz etkililiği puan ortalamasının daha yüksek olduğu belirlenmiştir. Akademisyen kadınlar ile yapılan bir çalışmada ise 41 yaş altında olanların mamografi engelleri ve KKMM engelleri puan ortalamasının 41 yaş ve üzerindekilerin puan ortalamasından daha yüksek olduğu belirlenmiştir [22]. $\mathrm{Bu}$ çalışmada eğitim düzeyi lise olan hemşirelerin KKMM öz etkililiği alt boyutu puan ortalaması eğitim düzeyi önlisans, lisans ve lisansüstü olan hemşirelerin puan ortalamalarında istatistiksel olarak anlamlı düzeyde düşük olduğu saptanmıştır. Eğitim düzeyi önlisans olanların meme kanseri taramalarında CSİMÖ mamografi engelleri alt boyutu puan ortalaması lisans mezunu hemşirelerin puan ortalamasından istatistiksel olarak anlamlı düzeyde yüksek olduğu saptanmıştır. Alvur ve ark. [21] çalışmasında da eğitim düzeyi yüksek olanların KKMM engelleri puan ortalamasının eğitim düzeyi düşük olanlardan daha düşük olduğu belirlenmiştir. Yüksek eğitim düzeyinin sağlık inancı ve davranışları üzerinde olumlu etkisi olduğu düşünülmüştür.

Sağlık İnanç Modeli’ne göre, bir kişinin kanseri önlemek için sigarayı bırakma gibi tedbirli davranışlar gösterme olasılığ 1 , kendilerinin de kansere ne kadar açık olduğu veya hastalığa yakalanabileceklerine ne kadar olasılık verdikleri ile ilişkilidir [23]. Bu çalışmada sigara kullananların sağlık motivasyonu ve KKMM öz etkililiği alt boyutu puan ortalaması sigara kullanmayanların puan ortalamasından istatistiksel olarak anlamlı düzeyde düşük olduğu saptanmıştır.

Bu çalışmada ailesinde meme kanseri öyküsü olanların meme kanseri taramalarında CSİMÖ duyarlılık ve sağlık motivasyonu alt boyutları puan ortalaması ailesinde meme kanseri olmayanların puan ortalamasından istatistiksel olarak anlamlı düzeyde yüksek olduğu saptanmıştır. Yine ailesinde meme kanseri öyküsü olmayanların meme kanseri taramalarında CSIMÖ mamografi engelleri alt boyutu puan ortalaması ailesinde meme kanseri olanların puan ortalamasından istatistiksel olarak anlamlı düzeyde yüksek olduğu saptanmıştır. Kılıç ve ark. [15] çalışmasında ailesie meme kanseri öyküsü olan öğrencilerin duyarlılık alt boyutları puan ortalaması ailesinde meme kanseri olmayanların puan ortalamasından istatistiksel olarak anlamlı düzeyde yüksek olduğu saptanmıştır. Alvur ve ark. [21] çalışmasında da ailesinde meme kanseri öyküsü olan kadınların duyarlılık alt boyutları puan ortalaması ailesinde meme kanseri olmayanların puan ortalamasından istatistiksel olarak anlamlı düzeyde yüksek olduğu belirlenmiştir. Erbil ve Bölükbaş'ın [19] çalışmasında da ailesinde meme kanseri öyküsü olan kadınların duyarlılık alt boyutları puan ortalaması ailesinde meme kanseri olmayanların puan 
Tablo 3. Meme kanseri taramalarında Champion’un Sağlık İnanç Modeli Ölçeği’nin tanıtıcı özelliklere göre dağılımı

\begin{tabular}{|c|c|c|c|c|c|c|c|c|}
\hline & Duyarlluk & Önemseme/Ciddiyet & Sağılık Motivasyonu & KKMM Yararları & KKMM Engelleri & $\begin{array}{l}\text { KKMMM } \\
\text { Oz-Etkililiğgi }\end{array}$ & Mamografi Yararları & Mamografi Engelleri \\
\hline Tanttcı özellikler & Ort. \pm ss & Ort. \pm ss & Ort. \pm ss & Ort. \pm ss & Ort. \pm ss & Ort. \pm ss & Ort. \pm ss & Ort. \pm ss \\
\hline $\begin{array}{ll}\text { Yas"* } & \\
18-24 & \text { a } \\
25-31 & \text { b } \\
32-38 & \text { c } \\
39 \text { ve üzeri } & \text { d }\end{array}$ & $\begin{array}{l}9,33 \pm 2,93 \\
8,58 \pm 2,45 \\
8,46 \pm 2,47 \\
8,14 \pm 2,62\end{array}$ & $\begin{array}{l}18,83 \pm 4,4,28 \\
18,6333,87 \\
18,10 \pm 3,99 \\
19,3444,62\end{array}$ & $\begin{array}{l}21,91 \pm 1,88 \\
20,19+2,22 \\
20,87 \pm 2,10 \\
20,31 \pm 3,22\end{array}$ & $\begin{array}{l}14,33 \pm 2,74 \\
15,392,41 \\
15,57 \pm 2,40 \\
15,27 \pm 3,07\end{array}$ & $\begin{array}{l}20,33 \pm 5,91 \\
21,1144,07 \\
20,52 \pm 3,67 \\
20,91 \pm 5,21\end{array}$ & $\begin{array}{l}36,58 \pm 6,6,27 \\
34,2556,20 \\
34,43 \pm 5,27 \\
35,00 \pm 6,72\end{array}$ & $\begin{array}{l}17,91 \pm 3,89 \\
19,013,09 \\
19,06+2,88 \\
18,39 \pm 3,65\end{array}$ & $\begin{array}{l}24,83 \pm 5,56 \\
25,9144,85 \\
27,244,74 \\
26,97 \pm 7,26\end{array}$ \\
\hline $\begin{array}{l}\text { Test deg̈eri } \\
\text { panlamlı fark }\end{array}$ & $\begin{array}{l}1,096 \\
0,351\end{array}$ & $\begin{array}{l}2,013 \\
0,112\end{array}$ & $\begin{array}{l}\substack{2,752 \\
\mathbf{0}, 043 \\
\text { a>b }} \\
a>b\end{array}$ & $\begin{array}{l}0,963 \\
0,410\end{array}$ & $\begin{array}{l}0,390 \\
0,760\end{array}$ & $\begin{array}{l}0,728 \\
0,536\end{array}$ & $\begin{array}{l}, 391 \\
0,245\end{array}$ & $\begin{array}{l}1,355 \\
0,256\end{array}$ \\
\hline $\begin{array}{l}\text { Cinsiyet** } \\
\text { Kadn } \\
\text { Erkek }\end{array}$ & $\begin{array}{l}8,37 \pm 2,51 \\
8,58 \pm 2,69\end{array}$ & $\begin{array}{l}18,87 \pm 4,26 \\
17,39 \pm 3,81\end{array}$ & $\begin{array}{l}20,66 \pm 2,65 \\
20,21 \pm 2,01\end{array}$ & $\begin{array}{l}15,48 \pm 2,68 \\
14,91+2,50\end{array}$ & $\begin{array}{l}20,43 \pm 4,45 \\
22,53 \pm 3,51\end{array}$ & $\begin{array}{l}35,01 \pm 6,04 \\
32,76+5,38\end{array}$ & $\begin{array}{l}18,63 \pm 3,32 \\
19,66+2.57\end{array}$ & $\begin{array}{l}26,77 \pm 6,02 \\
27,0744,06\end{array}$ \\
\hline $\begin{array}{l}\text { Test değeri } \\
\text { p }\end{array}$ & $\begin{array}{l}0,196 \\
0,658\end{array}$ & $\begin{array}{l}, 683 \\
0,195\end{array}$ & $\begin{array}{l}1,527 \\
0,217\end{array}$ & $\begin{array}{l}0,013 \\
0,136\end{array}$ & $\begin{array}{l}4,348 \\
\mathbf{0 , 0 0 1}\end{array}$ & $\begin{array}{l}1,601 \\
\mathbf{0 , 0 1 0}\end{array}$ & $\begin{array}{l}2,932 \\
0,029\end{array}$ & $\begin{array}{l}6,166 \\
0,721\end{array}$ \\
\hline 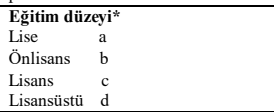 & $\begin{array}{l}8,37 \pm 2,59 \\
8,37 \pm 2,40 \\
8,28 \pm 2,60 \\
8,11 \pm 2,62\end{array}$ & $\begin{array}{l}18,03 \pm 3,76 \\
18,473,3,83 \\
18,8744,70 \\
18,94 \pm 4,19 \\
\end{array}$ & $\begin{array}{l}20,70 \pm 2,2,35 \\
20,8022,17 \\
20,45 \pm 2,89 \\
20,11 \pm 2,96\end{array}$ & $\begin{array}{l}16,18 \pm 2,80 \\
15,472,50 \\
15,41 \pm 2,63 \\
14,37 \pm 3,14\end{array}$ & $\begin{array}{l}19,40 \pm 3,35 \\
21,3144,05 \\
20,42 \pm 4,65 \\
20,74 \pm 5,07\end{array}$ & $\begin{array}{l}31,33 \pm 6,20 \\
34,2065,53 \\
35,62+6,13 \\
35,34 \pm 6,38\end{array}$ & $\begin{array}{l}18,77 \pm 4,22 \\
18,62+3,33 \\
18,95+3,04 \\
18,88 \pm 2,89\end{array}$ & $\begin{array}{l}26,51 \pm 3,52 \\
22,7555,73 \\
25,76+6,32 \\
26,7446,86\end{array}$ \\
\hline $\begin{array}{l}\text { Test değegri } \\
\text { p } \\
\text { Anlamlı fark }\end{array}$ & $\begin{array}{l}2,661 \\
0,073\end{array}$ & $\begin{array}{l}0,462 \\
0,709\end{array}$ & $\begin{array}{l}0,885 \\
0,449\end{array}$ & $\begin{array}{l}2,601 \\
0,052\end{array}$ & $\begin{array}{l}1,987 \\
0,116\end{array}$ & $\begin{array}{l}4,576 \\
0,004 \\
a<b, c, d\end{array}$ & $\begin{array}{l}0,268 \\
0,848\end{array}$ & $\begin{array}{l}3,332 \\
0,020 \\
b>c\end{array}$ \\
\hline $\begin{array}{l}\text { Medeni durum** } \\
\text { Evli } \\
\text { Bekar }\end{array}$ & $\begin{array}{l}8,37 \pm 2,47 \\
8,70 \pm 2,98\end{array}$ & $\begin{array}{l}18,13 \pm 3,76 \\
18,57 \pm 3,83\end{array}$ & $\begin{array}{l}20,57 \pm 2,50 \\
20,72 \pm 3,02\end{array}$ & $\begin{array}{l}15,36 \pm 2,65 \\
15,65 \pm 2,72\end{array}$ & $\begin{array}{l}20,74 \pm 4,24 \\
20,90 \pm 5,33\end{array}$ & $\begin{array}{l}34,54 \pm 5,90 \\
35,50 \pm 6,62\end{array}$ & $\begin{array}{l}18,84 \pm 3,21 \\
18,40 \pm 3,41\end{array}$ & $\begin{array}{l}26,72 \pm 5,71 \\
26,5060.06\end{array}$ \\
\hline Test değeri & $\begin{array}{l}1,873 \\
0.416\end{array}$ & $\begin{array}{l}0,450 \\
0,718\end{array}$ & $\begin{array}{l}1,506 \\
0707\end{array}$ & $\begin{array}{l}0,098 \\
0,489\end{array}$ & $\begin{array}{l}3,180 \\
0,814\end{array}$ & $\begin{array}{l}4,037 \\
0,324\end{array}$ & 0,9911 & $\begin{array}{l}0,324 \\
0.033\end{array}$ \\
\hline Cocuk saysıı * & & & & & & & & \\
\hline $\begin{array}{l}\text { Cocuk yok } \\
\text { 1-2 cocuk } \\
3-4 \text { couk } \\
\text { 5evu iereri }\end{array}$ & $\begin{array}{l}8,46+2,76 \\
8,41+2,53 \\
8,46+2,49 \\
7,94+2,20\end{array}$ & $\begin{array}{l}18,9844,64 \\
11,73+4,26 \\
18,103,81 \\
19,3844,43\end{array}$ & $\begin{array}{l}20,53 \pm 2,67 \\
20,52+2,67 \\
20,72 \pm 2,18 \\
20,7223,13\end{array}$ & $\begin{array}{l}15,17 \pm 2,89 \\
11,3332,75 \\
15,68 \pm 2,37 \\
15,3332,37\end{array}$ & $\begin{array}{l}20,8644,94 \\
20,084+42 \\
21,363+3,88 \\
22,383,3,91\end{array}$ & 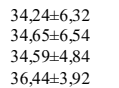 & $\begin{array}{l}18,58+3,23 \\
18,713+36 \\
18,973,04 \\
19,333,3,00\end{array}$ & $\begin{array}{l}27,18+6,11 \\
26,6885,566 \\
27,7855,80 \\
22,7885,34\end{array}$ \\
\hline Test değeri & 0,225 & 0,831 & 0,148 & 0,531 & 2,194 & 0,626 & 0,349 & $\begin{array}{l}0,852 \\
0.846\end{array}$ \\
\hline $\begin{array}{l}\text { p } \\
\text { Aile geliri * } \\
\text { Gelir giderden az } \\
\text { Gelir idere esit } \\
\text { Gelir giderden fazla }\end{array}$ & $\begin{array}{l}0,879 \\
8,36 \pm 2,51 \\
8,45 \pm 2,53 \\
8,382,59\end{array}$ & $\begin{array}{l}0,418 \\
18,40 \pm 3,97 \\
18,77 \pm 4,51 \\
18,664400\end{array}$ & $\begin{array}{l}0,931 \\
20,38 \pm 2,48 \\
20,552,90 \\
20,822,08\end{array}$ & $\begin{array}{l}0,661 \\
14,88 \pm 2,76 \\
15,60 \pm 2,78 \\
15,532,35\end{array}$ & $\begin{array}{l}0,088 \\
20,87 \pm 4,95 \\
20,2444,40 \\
21343,89\end{array}$ & $\begin{array}{l}0,598 \\
34,24 \pm 6,32 \\
34,65+5,54 \\
34,59+4,84\end{array}$ & $\begin{array}{l}0,768 \\
18,63 \pm 3,16 \\
18,72 \pm 3,34 \\
1902+3,16\end{array}$ & $\begin{array}{l}0,466 \\
27,16 \pm 6,13 \\
26,3555,64 \\
27.235,87\end{array}$ \\
\hline $\begin{array}{l}\text { Test değeri } \\
\text { p }\end{array}$ & $\begin{array}{l}0,042 \\
0.959\end{array}$ & $\begin{array}{l}0,225 \\
0,799\end{array}$ & $\begin{array}{l}0,730 \\
0.459\end{array}$ & $\begin{array}{l}2,382 \\
0,094\end{array}$ & $\begin{array}{l}2,190 \\
0,093\end{array}$ & $\begin{array}{l}0,617 \\
0,597\end{array}$ & $\begin{array}{l}0,432 \\
0,650\end{array}$ & $\begin{array}{l}0,848 \\
0,432\end{array}$ \\
\hline 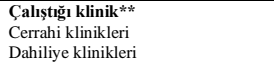 & $\begin{array}{l}8.24+2,50 \\
8.62 \pm 2,57\end{array}$ & $\begin{array}{l}18,64 \pm 4,29 \\
18,65 \pm 4,14\end{array}$ & $\begin{array}{l}20,46 \pm 2,70 \\
20,75 \pm 2,39\end{array}$ & $\begin{array}{l}15,35 \pm 2,54 \\
15,45 \pm 2,80\end{array}$ & $\begin{array}{l}20,82 \pm 4,50 \\
20,6844,20\end{array}$ & $\begin{array}{l}34,98 \pm 6,07 \\
34,26 \pm 5,89\end{array}$ & $\begin{array}{l}18,59 \pm 3,46 \\
19,04+2,92\end{array}$ & $\begin{array}{l}27,01 \pm 6,16 \\
26,575,20\end{array}$ \\
\hline Test değeri & $\begin{array}{l}0.007 \\
0.162\end{array}$ & $\begin{array}{l}0,038 \\
0,075\end{array}$ & $\begin{array}{l}1,561 \\
0282\end{array}$ & 3,061 & 0,389 & 0,120 & $\begin{array}{l}2,034 \\
0,192\end{array}$ & $\begin{array}{l}2,989 \\
0.81\end{array}$ \\
\hline $\begin{array}{l}\text { Pigara kullanma** } \\
\text { Evet } \\
\text { Hayir }\end{array}$ & $\begin{array}{l}.102 \\
8.49 \pm 2,45 \\
8.38 \pm 2,57\end{array}$ & $\begin{array}{l}18,98 \pm 3,96 \\
18,53 \pm 4,30\end{array}$ & $\begin{array}{l}, 202 \\
20,10 \pm 2,79 \\
20,74 \pm 2,48\end{array}$ & $\begin{array}{l}, 100 \\
14,94 \pm 2,93 \\
15,54+2,56\end{array}$ & $\begin{array}{l}21,29 \pm 4,36 \\
20,59 \pm 4,38\end{array}$ & $\begin{array}{l}32,95 \pm 6,10 \\
35,20 \pm 5,87\end{array}$ & $\begin{array}{l}18,192 \\
18,79 \pm 3,18 \\
18,79 \pm 3,26\end{array}$ & $\begin{array}{l}, 401 \\
27,03 \pm 5,63 \\
26,70 \pm 5,80\end{array}$ \\
\hline $\begin{array}{l}\text { Test değeri } \\
\text { p }\end{array}$ & $\begin{array}{l}0.3097,37 \\
0.270\end{array}$ & $\begin{array}{l}1,5,544,50 \\
0,386\end{array}$ & $\begin{array}{l}0,584,48 \\
\mathbf{0 , 4 2}\end{array}$ & $\begin{array}{l}3,205 \\
0,067\end{array}$ & $\begin{array}{l}0,025 \\
0,191\end{array}$ & $\begin{array}{l}0,2036 \\
0,030\end{array}$ & $\begin{array}{l}10,172,20 \\
0,1798 \\
0.998\end{array}$ & $\begin{array}{l}0,329 \\
0,689\end{array}$ \\
\hline $\begin{array}{l}\text { Alkol kullanma** } \\
\text { Evet } \\
\text { Hayir }\end{array}$ & $\begin{array}{l}8.60 \pm 2,01 \\
8.40 \pm 2,56\end{array}$ & $\begin{array}{l}17,25 \pm 22,22 \\
18,7224,15\end{array}$ & $\begin{array}{l}20,70 \pm 2,61 \\
20,582,57\end{array}$ & $\begin{array}{l}15,65 \pm 3,42 \\
15,38 \pm 2,61\end{array}$ & $\begin{array}{l}20,55 \pm 5,14 \\
20,7754,34\end{array}$ & $\begin{array}{l}32,90444,48 \\
347,765+89\end{array}$ & $\begin{array}{l}19,40 \pm 4,41 \\
18,75 \pm 3,16\end{array}$ & $\begin{array}{l}26,50 \pm 6,42 \\
26,80 \pm 5,72\end{array}$ \\
\hline Test değeri & $\begin{array}{l}1.760 \\
0.186\end{array}$ & $\begin{array}{l}1,11421 \\
0,128\end{array}$ & $\begin{array}{l}0,059 \\
0,845\end{array}$ & $\begin{array}{l}1,0711 \\
0,664\end{array}$ & $\begin{array}{l}0,029 \\
0,283\end{array}$ & $\begin{array}{l}1,687 \\
0,177\end{array}$ & $\begin{array}{l}1,758 \\
0,186\end{array}$ & $\begin{array}{l}0,368 \\
0,861\end{array}$ \\
\hline $\begin{array}{l}\text { Ailesinde meme kanseri öyküsüæ* } \\
\text { Evet }\end{array}$ & $12.42 \pm 3,04$ & $19,61 \pm 4,14$ & $21,57 \pm 1,74$ & $16,03 \pm 1,53$ & $20,03 \pm 5,75$ & $33,42 \pm 7,16$ & $18,96 \pm 3,87$ & $24,07 \pm 5,16$ \\
\hline Hayir & $8.09 \pm 2,21$ & $\begin{array}{l}18,57 \pm 4,22 \\
0,03,2\end{array}$ & $\frac{20,51 \pm 2,61}{207}$ & $\frac{15,34 \pm 2,72}{1086,}$ & $20,81 \pm 4,26$ & $\begin{array}{l}34,75 \pm 5,90 \\
050\end{array}$ & $\frac{18,78 \pm 3,19}{208}$ & $\begin{array}{r}27,03 \pm 5,75 \\
0,13,\end{array}$ \\
\hline Test değeri & $\begin{array}{l}6.629 \\
\mathbf{0 . 0 0 1}\end{array}$ & $\begin{array}{l}0,073 \\
0.225\end{array}$ & $\begin{array}{l}2,057 \\
\mathbf{0 , 4 2}\end{array}$ & $\begin{array}{l}12,868 \\
0.204\end{array}$ & $\begin{array}{l}4,109 \\
0.832\end{array}$ & $\begin{array}{l}0,562 \\
0,275\end{array}$ & $\begin{array}{l}2,984 \\
0.784\end{array}$ & $\begin{array}{l}0,183 \\
\mathbf{0 . 0 1 1}\end{array}$ \\
\hline
\end{tabular}

*One-Way ANOVA, ** Indenpendent Samples t-test Ort.: Ortalama, ss: Standart sapma 
ortalamasından istatistiksel olarak anlamlı düzeyde yüksek olduğu belirlenmiştir. Abolfotouh ve ark. [24] çalışmasında sağlık inanç modeli kapsamında ailesinde meme kanseri olanların algılanan güven düzeyinin ailesinde meme kanseri olmayanlara göre yüksek, algılanan engel düzeyinin ise daha düşük olduğu saptanmıştır. Ailede meme kanseri öyküsü olmasının konuya ilişkin farkındalığı ve duyarlılığı arttırdığı düşünülmüştür.

\section{Sonuç}

Hemşirelerin eğitim düzeyi, yaşı, cinsiyeti, sigara kullanması ve ailesinde meme kanseri olma; Champion'un Sağlık İnanç Modeli Ölçeği alt boyutlarının puan ortalamalarını etkilediği görülmüştür.

\section{Referanslar:}

1. Ramírez, K, Acevedo, F, Herrera, M.E, Ibáñez, C, Sánchez, C, Physical activity and breast cancer. Revistamédica de Chile, 2017, 145(1), 7584.

2. Akarsu, H.R, Alsaç, Y.S, Hemşirelik öğrencilerinin kendi kendine meme muayenesini bilme ve uygulama durumlarının belirlenmesi. Bozok Tip Dergisi, 2019, 9(3), 115-121.

3.Bingöl, D, Kılıcıkesen, E, Aydemir, C, Büyükkayacı Duman, N, Yaşlı kadınlara yönelik meme kanseri taramalarında güncel yaklaşımlar. Büyükkayacı Duman N (ed) Yaşlılık ve Kadın Sağlığı. 1. Baskı. Türkiye Klinikleri Ankara, 2019, pp.15-18.

4. Dolgun, E, Ezer, E.L, Öğrencilerin meme kanseri risk faktörleri yönünden incelenmesi. Ege Üniversitesi Hemşirelik Fakültesi Dergisi, $2018,34(2), 15-22$

5. Güner, İ.C, Tetik, A, Gönener, H.D, Kadınların kendi kendine meme muayenesi (KKMM) ile ilgili bilgi, tutum ve davranıșlarının belirlenmesi. Gaziantep Tip Dergisi, 2007, 13(2), 55-60.

6.Akram, M, Iqbal, M, Daniyal, M, Khan, A.U, Awareness and current knowledge of breast cancer. Biological research, 2017, 2,50(1), 33 doi:10.1186/s40659-017-0140-9.

7. Uzun, Ö, Karabulut, N, Karaman, Z, Hemşirelik öğrencilerinin kkmm ile ilgili bilgi ve uygulamaları. Atatürk Üniversitesi Hemşirelik Yüksekokulu Dergisi, 2004, 7, 33-41.

8. Siddharth, R, Gupta, D, Narang, R, Singh, P, Knowledge, attitude and practice about breast cancer and breast self-examination among women seeking out-patient care in a teaching hospital in central India. Indian Journal of Cancer, 2016, 53, 226-229.

9. Sama, C.B, Dzekem, B, Kehbila, J, Ekabe, C.J, Vofo, B, Ebu, N.L, Dingana, T.N, Angwafo, F, Awareness of breast cancer and breast selfexamination among female undergraduate students in a higher teachers training college in Cameroon. The Pan African medical journal, 2017, 28, 91. doi:10.11604/pamj.2017.28.91.10986

10. Sezen, S, Mamografi davranıș değişim süreci ölçeğinin (MDDSÖ) geçerlik ve güvenirlik çalışması. Halk Sağlığı Hemşireliği Anabilim Dalı. Yüksek Lisans Tezi, Manisa, 2017.

11. Sahin, T, Adıyaman Üniversitesi'nde çalısan bayanların kendi kendine meme muayenesiyle ilgili bilgi ve uygulamaları. Halk Sağlı̆ı̆ Ana Bilim Dalı, Yüksek Lisans Tezi, Elazı̆̆, 2012.

12. Gøtzsche, P.C, Jørgensen, K.J, Screening for breast cancer with mammography. Cochrane Database of Systematic Reviews, 2013, 4;(6):CD001877. doi:10.1002/14651858.

13.Løberg, M, Lousdal, M.L, Bretthauer, M, Kalager, M, Benefits and harms of mammography screening. Breast Cancer Res, 2015,17, 63:112 doi:10.1186/s13058-015-0525-z

14. Gözüm, S, Karayurt, O, Aydin, I, Meme kanseri taramalarında Champion'un sağlık inanç modeli ölçeğinin Türkçe uyarlamalarına iliş̧in sonuçlar. Hemşirelikte Araşttrma Geliştirme Dergisi, 2004, 1, 71-81.

15. Kılıç, D, Sağlam, R, Kara, Ö, Üniversite öğrencilerinde meme kanseri farkındalığını etkileyen faktörlerin incelenmesi. Meme Sağlığı Dergisi, 2009, 5(4), 195-199.

16. Arevian, M, Noureddine, S, Abboud, S, Beliefs related to breast cancer and breast cancer screening among Lebanese Armenian women. Health Care Women Int. 2011, 32(11): 972-89. doi 10.1080/07399332.2011.580405.
17. Pirzadeh, A, Application of the health belief model in breast selfexamination by Iranian female university students. Int $\mathrm{J}$ Cancer Manag. 2018 11(3), e7706. doi: 10.5812/ijcm.7706.

18. İz F.B, Tümer A, Assessment of breast cancer risk and belief in breast cancer screening among the primary healthcare nurses. J Cancer Educ. 2016 31(3), 575-581. doi: 10.1007/s13187-015-0977-y

19. Erbil, N, Bölükbaş, N, Beliefs, attitudes, and behavior of Turkish women about breast cancer and breast self-examination accordingto a Turkish version of the Champion health belief model scale. Asian Pacific J Cancer Prevention, 2012, 13(11), 5823-5828.

20. Karayurt, Ö, Dramalı, A, Adaptation of Champion's health belief model scale for Turkish women and evaluation of the selected variables associated with breast self-examination. Cancer Nursing, 2007, 30, 69-77.

21. Alvur, T.M, Çınar, N, Zengin, H, Health belief model and breast canser in Sakarya: a cross sectional study. Uluslararası Hakemli Akademik Spor Sağllk ve Tip Bilimleri Dergisi, 2019, (30), 52-67.

22. Kirag, N, Kizılkaya, M, Application of the Champion Health Belief Model to determine beliefs and behaviors of Turkish women academicians regarding breast cancer screening: A cross sectional descriptive study. BMC Women's Health 2019, 19, 132. https://doi.org/10.1186/s12905-019-0828-9

23. Bulduk, S, Yurt, S, Dinçer, Y, Ardıç, E, Sağlık davranışı modelleri. Düzce Üniversitesi Sağllk Bilimleri Enstitüsü Dergisi, 2015, 5(1), 2834

24. Abolfotouh, M.A, Bani Mustafa, A.A, Mahfouz, A.A, Al-Assiri M.H, Juhani A.F, Alaskar A.S, Using the health belief model to predict breast self examination among Saudi women. BMC Public Health $2015,15,1163$

http://edergi.cbu.edu.tr/ojs/index.php/cbusbed isimli yazarın CBU-SBED başlıklı eseri bu Creative Commons Alıntı-Gayriticari4.0 Uluslararası Lisansı ile lisanslanmıştır.

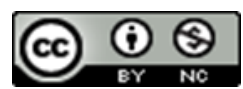

